\title{
A Study on Age at Menarche of School Going Girls in Bangladesh
}

\author{
Akifa Akther, Rafiqul Islam* \\ Department of Population Science and Human, Resource Development, University of Rajshahi, Rajshahi , 6205, Bangladesh
}

\begin{abstract}
The aim of this research is to study age at menarche of school going girls in Bangladesh. For this purpose, the data is acquired from Nilphamary Government Girls High School of the classes of five, six, seven and eight during1st June$30^{\text {th }}$ June, 2008. In this study, it is to investigate the pattern of age at menarche of total respondents and the pattern of height, weight and body mass index by the age of the respondents in accordance with menarche and non-menarche. The age range of the respondents was between 10 to 14 years. Chi-square test and logistic regression analysis are employed in this paper. This study also displays the association of age at menarche with socio-demographic variables of respondents. It is realized from the association that early menarche for school going girl's height, weight, father income, body mass index, time spent by watching television and father educational qualification were highly significant but mother educational qualification, mother occupation, father occupation, number of siblings, order of birth, time spent by playing and mother time spent were insignificant. In logistic analysis, it was found that only height, weight and time spent by watching TV were significant which have positive effects on age at menarche.
\end{abstract}

Keywords Age at menarche, Chi-square test, Logistic regression analysis, Model validation technique

\section{Introduction}

Menarche is a part of complex process of physical and emotional development of a girl. The cyclical release of blood, mucous in certain other substances per vagina from uterus in the reproductive span, that is, ages of 15 to 49 years of life of the female at standard period of about 28 days is called menstruation. The cyclic production of humorous that culminates in the release of a mature egg, that is, ovum, is called the menstrual cycle and the first menstrual cycle is called menarche. Menarche is the first menstrual period, or first menstrual bleeding of the female of human beings. From both social and medical perspectives menarche is influenced by both genetic and environmental factors, especially nutritional status. The average age of menarche has declined over the last century but the magnitude of the decline and the factors responsible remain subjects of contention.

Age at menarche is an important indicator of future diseases. Early onset of menarche is a well-established risk factor for breast cancer[1]. It might also increase the risk of heart disease[2]. Late menarche may, however, be positively associated with the risk of developing Alzheimer's disease [3]. Age at menarche may also affect reproductive function. Early menarche may be a marker for reproductive fitness or,

* Corresponding author:

rafique_pops@yahoo.com (Rafiqul Islam)

Published online at http://journal.sapub.org/ajmms

Copyright (C) 2011 Scientific \& Academic Publishing. All Rights Reserved at least, a marker for the onset of childbearing years[4]. In consequence, early menarche is the main cause of high fertility as well as high mortality. Changes in mean age at menarche over time may underlie the changing patterns of these diseases. On the other hand, not every girl follows the typical pattern, and some girls ovulate before the first menstruation. Although unlikely, it is possible for a girl who has engaged in sexual intercourse shortly before her menarche to conceive and become pregnant, which would delay her menarche until after the birth. This goes against the widely held assumption that a woman cannot become pregnant until after menarche.

Since the $18^{\text {th }}$ century secular trends in age at menarche have been described. Results from Western countries are consistent in their descriptions of decreasing age at menarche over time in cohorts of women born prior to 1940[5]. The results from later cohorts are less consistent, no changes, increases[6] and decereases all having been reported[7]. With respect to especially Bangladeshi populations, some researchers[ $[8-10,4]$ have studied nutritional status and age at menarche, age at menarche and postmenarcheal growth and age at menarche and marriage.

Therefore, the main objectives of this research paper are addressed below:

i) To study the secular patterns in age at menarche, height, weight, and body mass index (BMI) of school going girls of Nilphamary district in Bangladesh.

ii) To investigate the relation between menarcheal age and anthropometric measures and socio-demographic variables. 
This paper is organized into five sections that is addressed in the followings:

First section is introduction in which background of the study, review of literature and objectives of this study are briefly described. Section two contains data and data source of this study. Methodology is discussed in section three in which Chi-square test, logistic regression analysis and model validation technique are shortly narrated. Results and discussions are discussed in section four. Section five contains the conclusion of this research. References are placed at the end of this manuscript.

\section{Data Source of This Study}

The data of 248 sample unit was collected from Nilphamary Government Girls High School in Bangladesh of the classes of five, six, seven and eight during1st June- $30^{\text {th }}$ June, 2008 by purposively. By through questionnaire age at menarche, menstrual disturbance and socio- demographic characteristics of the respondents were collected at the time of data collection.

\section{Methodology}

\subsection{Chi-square Test}

In this paper, Chi-square test is used to find out the association of menarche with socio-demographic variables.

\subsection{Logistic Regression Analysis}

The logistic regression analysis is one of the most important methods for the successful application in all discipline of knowledge. This method is very useful for identifying various risk factors in case of qualitative outcome variables. Cox $[11,12]$ has developed linear logistic regression model. The logistic regression model can be used not only to identify risk factors but also to predict the probability of success. This model expresses a qualitative dependent variable as a function of several independent variables, both qualitative and quantitative[13]. The dependent variable (Y) used in this logistic model is classified in the following way:

$$
Y=\text { Age at menarche }=\left\{\begin{array}{l}
1, \text { if causes of menarche is yes } \\
0, \text { otherwise }
\end{array}\right.
$$

The explanatory variables employed in this model are presented in the respective table.

\subsection{Model Validation Technique}

The cross validity prediction power (CVPP) is applied to weigh up the accuracy and consistency of the model. The algebraic formula for CVPP is addresed by

$$
\rho_{c v}^{2}=1-\frac{(n-1)(n-2)(n+1)}{n(n-k-1)(n-k-2)}\left(1-R^{2}\right) .
$$

In which $\mathrm{n}$ is the number of classes, $\mathrm{k}$ is the number of explanatory variables in the fitted model and the crossvalidated $\mathrm{R}$ is the correlation between observed and predicted values of the dependent variable[14]. The shrinkage and contraction of the model is the positive value of $\lambda=\left(\rho_{c v}^{2}\right.$ - $\mathrm{R}^{2}$ ); where $\rho_{c v}^{2}$ is CVPP \& $\mathrm{R}^{2}$ is the coefficient of determination of the model. $1-\lambda$ is the stability of $R^{2}$ of the model. Closer the value of $\lambda$ to zero, the better is the prediction. The estimated CVPP related to their $\mathrm{R}^{2}$ and information on model fittings are presented in the result and discussion section. CVPP was employed as model validation test by Islam $[15,16]$ and Islam et al.[17,18].

\section{Results and Discussion}

\subsection{Background Characteristics of the Respondents}

Background characteristics of the respondents are important to know the characteristics or nature of the data before performing any statistical analysis. In order to see the nature of the characteristics of data, frequency distribution and graphical representation could be very useful due to the goal of this study. For this, we perform necessary frequency tables presented below.

In Table 1, it is found that $15.3 \%$ respondent are in class five, $40.7 \%$ respondent are in class six, $25.4 \%$ are in class seven and $18.5 \%$ are in class eight.

Table 1. The frequency distribution of the respondents by class

\begin{tabular}{cccc}
\hline Class & Frequency & Percent & Cumulative Percent \\
\hline 5 & 38 & 15.3 & 15.3 \\
6 & 101 & 40.7 & 56.0 \\
7 & 63 & 25.4 & 81.5 \\
8 & 46 & 18.5 & 100.0 \\
Total & 248 & 100.0 & \\
\hline
\end{tabular}

From the Table 2 it is realized that 19 respondent's year of birth is 1994 , which is $7.7 \%$. 49 respondent's year of birth is 1995 , which is $19.8 \%$. 82 respondent's year of birth is 1996 , which is $33.1 \%$. 76 respondent's year of birth is 1997 , which is $30.6 \%$. 22 respondent's year of birth is 1998 , which is $8.9 \%$.

Table 2. The distribution of the respondents by year of birth

\begin{tabular}{cccc}
\hline Year of birth & Frequency & Percent & Cumulative Percent \\
\hline 1994 & 19 & 7.7 & 7.7 \\
1995 & 49 & 19.8 & 27.4 \\
1996 & 82 & 33.1 & 60.5 \\
1997 & 76 & 30.6 & 91.1 \\
1998 & 22 & 8.9 & 100.0 \\
Total & 248 & 100.0 & \\
\hline
\end{tabular}

It is observed in Table 3 that $82.7 \%$ respondents are Muslim and $17.3 \%$ are Hindu. We obtain from the Table 4 that $2.4 \%$ respondent has 1 number of siblings. $37.9 \%$ respondent has 2 and 3 number of siblings. 11.7\% respondent has 4 numbers of siblings. $6.9 \%$ respondent has 5 numbers of siblings and $6.9 \%$ respondent has 8 numbers of siblings.

Table 3. Frequency distribution of the respondents by religion

\begin{tabular}{cccc}
\hline Religion & Frequency & Percent & Cumulative Percent \\
\hline Islam & 205 & 82.7 & 82.7 \\
Hindu & 43 & 17.3 & 100.0 \\
Total & 248 & 100.0 & \\
\hline
\end{tabular}


Table 4. The frequency distribution of the respondents by number of siblings

\begin{tabular}{cccc}
\hline $\begin{array}{c}\text { Number of } \\
\text { siblings }\end{array}$ & Frequency & Percent & $\begin{array}{c}\text { Cumulative } \\
\text { Percent }\end{array}$ \\
\hline 1 & 6 & 2.4 & 2.4 \\
2 & 94 & 37.9 & 40.3 \\
3 & 94 & 37.9 & 78.2 \\
4 & 29 & 11.7 & 89.9 \\
5 & 17 & 6.9 & 96.8 \\
$6+$ & 8 & 3.2 & 100.0 \\
Total & 248 & 100.0 & \\
\hline
\end{tabular}

In Table 5 , it is seen that $40.3 \%$ respondents are spent time with there mother less than 3 hours. $36.3 \%$ respondents spent time with there mother 3 to 7 hours. $23.4 \%$ respondents spent time with there mother more than 7 hours. We get 136 respondents are spent one hour time by playing, which is $54.8 \%$. 70 respondents are spent 2 hour time by playing, which is $28.2 \%$. 9 and 2 respondents are spent time 3 and 5 hour respectively, which is $3.6 \%$ and $0.8 \%$ respectively. 31 respondents are not like playing, there percentage is $12.5 \%$.

Table 5. The frequency distribution of the respondents by mother time spent

\begin{tabular}{cccc}
\hline $\begin{array}{c}\text { Time } \\
\text { (hours) }\end{array}$ & Frequency & Percent & $\begin{array}{c}\text { Cumulative Per- } \\
\text { cent }\end{array}$ \\
\hline$<3$ & 100 & 40.3 & 40.3 \\
$3-7$ & 90 & 36.3 & 76.6 \\
$7+$ & 58 & 23.4 & 100.0 \\
Total & 248 & 100.0 & \\
\hline
\end{tabular}

Table 6. The frequency distribution of the respondents by time spent for playing

\begin{tabular}{cccc}
\hline $\begin{array}{c}\text { Time } \\
\text { (hours) }\end{array}$ & Frequency & Percent & $\begin{array}{c}\text { Cumulative Per- } \\
\text { cent }\end{array}$ \\
\hline 0.00 & 31 & 12.5 & 12.5 \\
1.00 & 136 & 54.8 & 67.3 \\
2.00 & 70 & 28.2 & 95.6 \\
3.00 & 9 & 3.6 & 99.2 \\
5.00 & 2 & 0.8 & 100.0 \\
Total & 248 & 100.0 & \\
\hline
\end{tabular}

It is observed from the Table 7 that 25 respondents are not like watching $\mathrm{TV}$, which is $10.1 \% .90$ respondents are spent one hour by watching TV, which is $36.3 \%$. 102 respondents are spent two hours by watching TV, which is $41.1 \%$. 20 and 11 respondents are spent 3 and 4 hours by watching TV respectively, which is $8.1 \%$ and $4.4 \%$ respectively.

Table 7. The frequency distribution of the respondents by time of watching television

\begin{tabular}{cccc}
\hline Time (hours) & Frequency & Percent & Cumulative Percent \\
\hline 0.00 & 25 & 10.1 & 10.1 \\
1.00 & 90 & 36.3 & 46.4 \\
2.00 & 102 & 41.1 & 87.5 \\
3.00 & 20 & 8.1 & 95.6 \\
4.00 & 11 & 4.4 & 100.0 \\
Total & 248 & 100.0 & \\
\hline
\end{tabular}

It is indicated that 22 respondent's age is 10 , which is $8.9 \%$. 76 respondent's age is 11 , which is $30.6 \%$. 82 respondent's age is 12 , which is $33.1 \%$. 49 respondent's age is 13 , which is $19.8 \%$. 19 respondent's age is 14 , which is $7.7 \%$ from the Table 8 . In Table 9, we find that $127-131 \mathrm{~cm}$ height is 4 numbers of respondents, which is $1.6 \% .132-136 \mathrm{~cm}$ height is 15 numbers of respondents, which is $4.4 \% .137$ $-141 \mathrm{~cm}$ height is 16 respondents that is $6.5 \% .142-146 \mathrm{~cm}$ height is 34 number of respondents, which is $13.7 \%$. 147-151 $\mathrm{cm}$ height is 67 respondents which is $27 \%$. $152-156 \mathrm{~cm}$ height is 83 respondents $(33.5 \%) .157$ and more $\mathrm{cm}$ height is $13.3 \%$. We realize from the Table 10 that $20.6 \%$ respondent's weight is $41-45$ (in $\mathrm{kg}$ ), which is maximum and $2.4 \%$ respondent's weight is above 51 , which is minimum.

Table 8. The frequency distribution of the respondents by age

\begin{tabular}{cccc}
\hline Age & Frequency & Percent & Cumulative Percent \\
\hline 10 & 22 & 8.9 & 8.9 \\
11 & 76 & 30.6 & 39.5 \\
12 & 82 & 33.1 & 72.6 \\
13 & 49 & 19.8 & 92.3 \\
14 & 19 & 7.7 & 100.0 \\
Total & 248 & 100.0 & \\
\hline
\end{tabular}

Table 9. Frequency distribution by height

\begin{tabular}{cccc}
\hline Height $(\mathrm{cm})$ & Frequency & Percent & Cumulative Percent \\
\hline $127-131$ & 4 & 1.6 & 1.6 \\
$132-136$ & 11 & 4.4 & 6.0 \\
$137-141$ & 16 & 6.5 & 12.5 \\
$142-146$ & 34 & 13.7 & 26.2 \\
$147-151$ & 67 & 27.0 & 53.2 \\
$152-156$ & 83 & 33.5 & 86.7 \\
$157+$ & 33 & 13.3 & 100.0 \\
Total & 248 & 100.0 & \\
\hline
\end{tabular}

Table 10. Frequency distribution of respondents by weight

\begin{tabular}{cccc}
\hline Weight & Frequency & Percent & Cumulative Percent \\
\hline $21-25$ & 13 & 5.2 & 5.2 \\
$26-30$ & 31 & 12.5 & 17.7 \\
$31-35$ & 48 & 19.4 & 37.1 \\
$36-40$ & 78 & 31.5 & 68.5 \\
$41-45$ & 51 & 20.6 & 89.1 \\
$46-50$ & 21 & 8.5 & 97.6 \\
$51+$ & 6 & 2.4 & 100.0 \\
Total & 248 & 100.0 & \\
\hline
\end{tabular}

It is seen from the table that $148(59.7 \%)$ respondents are passing their menstruation situation and 100 (40.3\%) respondents are not passing this situation. We get 1 respondent's age at menarche is 8 , which is $0.4 \%$. 2 respondent's age at menarche is 9 that is $0.8 \%$. 30 respondent's age at menarche is $10(12.1 \%) .45$ respondent's age at menarche is 11 , which is $18.1 \%$. 49 respondent's age at menarche is 12 (19.8\%). 18 respondent's age at menarche is $13(7.3 \%)$ as well as 3 respondent's age at menarche is 14 , which is $1.2 \%$. Moreover, age distribution of non menarche students is presented in Table 13.

Table 11. The frequency distribution of the respondents by menarche (yes/no)

\begin{tabular}{cccc}
\hline Menarche & Frequency & Percent & Cumulative Percent \\
\hline Yes & 148 & 59.7 & 59.7 \\
No & 100 & 40.3 & 100.0 \\
Total & 248 & 100.0 & \\
\hline
\end{tabular}


Table 12. The frequency distribution of the respondents by age at menarche

\begin{tabular}{cccc}
\hline Age at menarche & Frequency & Percent & Cumulative Percent \\
\hline 9 & 3 & 1.2 & 2.7 \\
10 & 30 & 12.1 & 22.3 \\
11 & 45 & 18.1 & 52.7 \\
12 & 49 & 19.8 & 85.8 \\
13 & 18 & 7.3 & 98.0 \\
14 & 3 & 1.2 & 100.0 \\
Total & 148 & 59.7 & \\
\hline
\end{tabular}

Table 13. The frequency distribution of the age of non menarche students

\begin{tabular}{cccc}
\hline Age & Frequency & Percent & Cumulative Percent \\
\hline 10 & 21 & 21.0 & 21.0 \\
11 & 44 & 44.0 & 65.0 \\
12 & 29 & 29.0 & 94.0 \\
13 & 6 & 6.0 & 100.0 \\
Total & 100 & 100.0 & \\
\hline
\end{tabular}

In Table 14, it is found that maximum number of respondents (29\%) belong to 9000-13000 income group where as minimum number are in the age group 21000 and above.

Table 14. The frequency distribution of the respondents by father income

\begin{tabular}{cccc}
\hline Income (In Taka) & Frequency & Percent & Cumulative Percent \\
\hline$<5000$ & 39 & 15.7 & 15.7 \\
$5000-9000$ & 61 & 24.6 & 40.3 \\
$9000-13000$ & 72 & 29.0 & 69.4 \\
$13000-17000$ & 41 & 16.5 & 85.9 \\
$17000-21000$ & 21 & 8.5 & 94.4 \\
$21000+$ & 14 & 5.6 & 100.0 \\
Total & 248 & 100.0 & \\
\hline
\end{tabular}

From the table we get 192 respondent's body mass index (BMI) is below 18.5 , which means that $77.4 \%$ are under weight. 56 respondent's BMI is 18.5-24.99, which indicates
$22.6 \%$ belongs to normal weight. It is observed from the Table 16 that mean height is higher in age 13 , which is 151.467 and mean height is lowest in age 10 (142.471). Mean weight is highest (42.053) in age 14 and mean weight is lowest in age 10, which is 30 . Mean BMI is highest in the age 14 , which is 18.428 and mean BMI is lowest in age 10, which is 15.072 . The mean height, weight and BMI of total respondents are $149.08,37.180$ and 16.927 respectively.

Table 15. The frequency distribution of the respondents by BMI

\begin{tabular}{cccc}
\hline BMI $\left(\mathrm{kg} / \mathrm{cm}^{2}\right)$ & Frequency & Percent & Cumulative Percent \\
\hline$<18.5$ & 192 & 77.4 & 77.4 \\
$18.5-24.99$ & 56 & 22.6 & 100.0 \\
Total & 248 & 100.0 & \\
\hline
\end{tabular}

It is apprehended from the following table of menarche students that mean height is highest (152.459) in age 13 and mean height is lowest (149.68) in age 10. Mean weight is highest in age 13, which is 42.698 and mean weight is lowest in age 10 , which is 30 . Mean BMI is highest in age 14 , which is 18.535 and mean BMI is lowest in age 10 , which is 13.358 . The mean height, weight and BMI of total menarche respondents are $151.816,41.5$ and 18.008 respectively.

From the Table 18 it is comprehended that non-menarche students mean height is highest (146.882) in age 12 and mean height is lowest in age 10 , which is 142.119 . Mean weight is highest in age 12 , which is 33.862 and mean weight is lowest in age 10 , which is 30 . Mean BMI is highest in age 14 that is 15.724 and mean BMI is lowest in age 10 , which is 14.778 . For total non-menarche respondents, mean height, weight and BMI are 145.034, 32.350 and 15.325 respectively.

Table 16. Mean values and standard deviations in height, weight and body mass index by age of total number of respondents

\begin{tabular}{|c|c|c|c|c|c|c|c|}
\hline \multirow{2}{*}{ Age } & \multirow{2}{*}{$\begin{array}{c}\text { Number of re- } \\
\text { spondent }\end{array}$} & \multicolumn{2}{|c|}{ Height $(\mathrm{cm})$} & \multicolumn{2}{|c|}{ Weight (kg) } & \multicolumn{2}{|c|}{ BMI } \\
\hline & & Mean & SD & Mean & $\mathrm{SD}$ & Mean & $\mathrm{SD}$ \\
\hline 10 & 22 & 142.471 & 7.556 & 30.00 & 5.912 & 15.072 & 2.511 \\
\hline 11 & 76 & 147.688 & 7.405 & 36.184 & 7.417 & 16.791 & 2.149 \\
\hline 12 & 82 & 150.325 & 6.146 & 38.317 & 5.497 & 16.598 & 2.446 \\
\hline 13 & 49 & 151.467 & 4.965 & 41.347 & 6.434 & 17.936 & 2.508 \\
\hline 14 & 19 & 150.796 & 7.723 & 42.053 & 4.503 & 18.428 & 1.932 \\
\hline Total & 248 & 149.082 & 7.027 & 37.810 & 7.022 & 16.927 & 2.473 \\
\hline
\end{tabular}

Table 17. Mean values and standard deviations (SD) in height, weight and BMI by age of menarche students

\begin{tabular}{cccccccc}
\hline \multirow{2}{*}{ Age at menarche } & $\begin{array}{c}\text { Number of respon- } \\
\text { dents }\end{array}$ & \multicolumn{2}{c}{ Height } & \multicolumn{2}{c}{ Weight } & \multicolumn{2}{c}{ BMI } \\
\cline { 2 - 7 } & 1 & 149.68 & - & Mean & SD & Mean & SD \\
\hline 10 & 32 & 150.971 & 5.278 & 41.156 & 5.815 & 18.358 & - \\
11 & 53 & 152.208 & 5.544 & 40.755 & 4.918 & 17.623 & 2.069 \\
12 & 43 & 152.459 & 3.819 & 42.698 & 5.54 & 18.344 & 2.242 \\
13 & 19 & 150.796 & 7.723 & 42.053 & 4.503 & 18.553 & 2.169 \\
14 & 148 & 151.816 & 5.358 & 41.5 & 5.341 & 18.008 & 2.169 \\
Total & & & & & & &
\end{tabular}

Table 18. Mean values and standard deviations (SD) in height, weight and body mass index by age of non-menarche students

\begin{tabular}{cccccccc}
\hline \multirow{2}{*}{ Age } & \multirow{2}{*}{$\begin{array}{c}\text { Number of non-menarche stu- } \\
\text { dents }\end{array}$} & \multicolumn{2}{c}{ Height } & \multicolumn{2}{c}{ Weight } & \multicolumn{2}{c}{ BMI } \\
\cline { 3 - 7 } & 21 & Mean & SD & Mean & SD & Mean & SD \\
\hline 10 & 44 & 142.119 & 7.555 & 30.000 & 6.058 & 14.778 & 2.341 \\
11 & 29 & 145.299 & 5.762 & 32.568 & 6.307 & 15.347 & 2.137 \\
12 & 6 & 146.882 & 5.762 & 33.862 & 3.270 & 15.724 & 1.605 \\
13 & 100 & 144.356 & 6.704 & 31.666 & 3.386 & 15.157 & 0.481 \\
Total & & 145.034 & 7.269 & 32.350 & 5.494 & 15.325 & 1.986 \\
\hline
\end{tabular}


Table 19. Mean difference between menarche and non-menarche in monthly income, number of still birth, order of birth, mother time spend, time spend in play, time spend in watch TV, age, height, weight and BMI

\begin{tabular}{|c|c|c|c|c|c|c|c|}
\hline \multirow{2}{*}{ Variable } & \multicolumn{3}{|c|}{ Menarche } & \multicolumn{3}{|c|}{ Non-menarche } & \multirow{2}{*}{$\begin{array}{c}\text { Mean } \\
\text { difference }\end{array}$} \\
\hline & $\mathrm{N}$ & Mean & $\mathrm{SD}$ & $\mathrm{N}$ & Mean & SD & \\
\hline Father income & 148 & 12537.16 & 7000.51 & 100 & 9765.00 & 4022.32 & 2772.162 \\
\hline No. of still birth & 148 & 2.89 & 1.04 & 100 & 2.99 & 1.19 & -0.10 \\
\hline Order of birth & 148 & 1.9459 & 1.0991 & 100 & 1.9500 & 1.2822 & -0.0041 \\
\hline Mother time spend & 148 & 5.4122 & 4.0321 & 100 & 5.2000 & 3.6735 & 0.2144 \\
\hline Time spend in play & 148 & 1.3041 & 0.7158 & 100 & 1.2000 & 0.8762 & 0.1041 \\
\hline Time spent in TV & 148 & 1.7500 & 0.9680 & 100 & 1.3900 & 0.8396 & 0.3600 \\
\hline Age & 148 & 12.32 & 0.980 & 100 & 11.20 & 0.84 & 1.12 \\
\hline Height $(\mathrm{cm})$ & 148 & 151.8165 & 5.3583 & 100 & 145.034 & 7.2699 & 6.7825 \\
\hline Weight $(\mathrm{kg})$ & 148 & 41.5000 & 5.3408 & 100 & 32.3500 & 5.4945 & 9.15 \\
\hline BMI & 148 & 18.0083 & 2.1688 & 100 & 15.3259 & 1.9861 & 2.6824 \\
\hline
\end{tabular}

Table 20. Chi-square value and significant level of some demographic and socio-economic variables for age at menarche

\begin{tabular}{|c|c|c|c|c|c|}
\hline \multirow{2}{*}{ Characteristics } & \multicolumn{2}{|c|}{ Chi-square value } & \multirow{2}{*}{ P-value } & \multirow{2}{*}{ d.f. } & \multirow{2}{*}{ Significant level } \\
\hline & Calculated value & Tabulated value & & & \\
\hline Height & 52.965 & 5.991 & 0.000 & 2 & Significant \\
\hline Weight & 84.096 & 5.991 & 0.000 & 2 & Significant \\
\hline Father income & 11.020 & 5.991 & 0.004 & 2 & Significant \\
\hline BMI & 39.092 & 3.841 & 0.000 & 1 & Significant \\
\hline Time spent by watching TV & 3.922 & 3.841 & 0.048 & 1 & Significant \\
\hline Father educational qualification & 4.722 & 3.841 & 0.030 & 1 & Significant \\
\hline Mother educational qualification & 1.534 & 3.841 & 0.215 & 1 & Insignificant \\
\hline Number of siblings & 0.842 & 5.991 & 0.656 & 2 & Insignificant \\
\hline Time spend by playing & 0.540 & 3.841 & 0.463 & 1 & Insignificant \\
\hline Order of birth & 1.194 & 5.991 & 0.550 & 2 & Insignificant \\
\hline Father occupation & 0.327 & 3.841 & 0.567 & 1 & Insignificant \\
\hline Mother occupation & 0.002 & 3.841 & 0.964 & 1 & Insignificant \\
\hline Mother time spend & 0.550 & 5.991 & 0.760 & 2 & Insignificant \\
\hline
\end{tabular}

The following table exhibits the mean differences in father income, number of still birth, order of birth, mother time spent, time spent in playing, time spent by watching $\mathrm{TV}$, age, height, weight and body mass index in case of menarche and non-menarche respondents. The mean difference explained that father income was larger for menarche students than that of non-menarche students. Number of still birth and birth order were not significantly related to menarche and nonmenarche situation. Mother time spent, time spent by playing and time spent by watching TV were larger than that of non-menarche respondents. The mean differences in age, height, weight and BMI of menarche were some what larger than those of non-menarche respondents.

\subsection{Association}

The contingency analysis investigated the degree or strength of association together the dependency criterion between the selected variables. Examination of association is performed by means of contingency table that is displayed in Table 20. Demographic and socio-economic variables are responsible for early menarche. We see from the table that in case of causes of early menarche for school going girl's height, weight, father income, body mass index time spent by watching television and father educational qualification are highly significant and mother educational qualification, mother occupation, father occupation, number of siblings, order of birth, time spent by playing and mother time spent are insignificant.

\subsection{Logistic Regression Analysis}

The results of logistic regression analysis are demonstrated in Table 21. The table exhibits that only three variables out of six explanatory variables are statistically significant and the rest of the variables are statistically insignificant. A brief description of the significant variables is given below:

One of the most important factors for menarche is height. The estimated regression co-efficient for height group $136-145 \mathrm{~cm}$ and for height group $146 \mathrm{~cm}$ and above are 1.236 and 1.853 respectively, which means it has positive impact on menarche. The odds ratio belongs to the height groups $136-145$ and $146+\mathrm{cm}$ are 3.441 and 6.378 respectively. It is indicated that 3.441 and 6.378 times higher risk of menarche than that of height group 126-135 cm. From this table it is realized that the estimated regression co-efficient for weight groups $31-40 \mathrm{~kg}$ and $40+\mathrm{kg}$ are 1.374 and 3.490 respectively that is positively affect on menarche. The odds ratio for the weight groups $31-40 \mathrm{~kg}$ and $40+\mathrm{kg}$ are 3.950 and 32.779 respectively which indicated that 3.950 and 32.779 times higher risk of menarche than that of weight groups $21-30 \mathrm{~kg}$. The estimated regression coefficients for time spent by watching TV of the respondents above one hour is 0.586 which indicated that it has positive effect on menarche. The odds ratio for above one hour time spent by watching TV is 1.797 . It is indicated that the risk of menarche for above one hour time spent by watching TV 1.797 times higher than that of under one hour.

In the fitted logistic model, it is provided that $\mathrm{R}^{2}=0.598$, $\rho_{c v}^{2}=0.579493$, and shrinkage coefficient $(\lambda)=0.018507137$. 
From these statistics, it is seen that the shrinkage coefficient is very small. Moreover, the stability of $\mathrm{R}^{2}$ of the model is more than $99 \%$. Hence, it is concluded that the model is better fit.

Table 21. Logistic regression estimates for age at menarche with demographic and socio-economic variables

\begin{tabular}{|c|c|c|c|}
\hline Variables & $\mathrm{B}$ & $\begin{array}{l}\text { Significance } \\
\text { (p-value) }\end{array}$ & Odds ratio \\
\hline \multicolumn{4}{|l|}{ Height: } \\
\hline $126-135 \mathrm{~cm}(\mathrm{R})$ & - & 0.016 & 1.00 \\
\hline $136-145 \mathrm{~cm}$ & 1.514 & 0.060 & 4.545 \\
\hline $145 \mathrm{~cm}+$ & 2.213 & 0.009 & 9.144 \\
\hline \multicolumn{4}{|l|}{ Weight: } \\
\hline $21-30 \mathrm{~kg}(\mathrm{R})$ & - & 0.000 & 1.00 \\
\hline $31-40 \mathrm{~kg}$ & 1.374 & 0.015 & 3.950 \\
\hline $40 \mathrm{~kg}+$ & 3.490 & 0.000 & 32.779 \\
\hline \multicolumn{4}{|l|}{ Father Income: } \\
\hline$<10000(\mathrm{R})$ & - & 0.725 & 1.00 \\
\hline $10000-20000$ & -0.242 & 0.531 & 0.785 \\
\hline $20000+$ & 7.013 & .623 & 1111.519 \\
\hline \multicolumn{4}{|c|}{ Time spent by watching TV: } \\
\hline$<1 \mathrm{hr}(\mathrm{R})$ & - & - & 1.00 \\
\hline $1 \mathrm{hr}+$ & 0.586 & 0.092 & 1.797 \\
\hline \multicolumn{4}{|c|}{$\begin{array}{l}\text { Father's educational qualifica- } \\
\text { tion. }\end{array}$} \\
\hline $\begin{array}{c}\text { tion: } \\
\text { tisc }\end{array}$ & - & - & 1.00 \\
\hline $\begin{array}{c}\text { HSC (R) } \\
\text { HSC and Above }\end{array}$ & 0.172 & 0.657 & 1.187 \\
\hline Constant: & -3.394 & 0.000 & 0.034 \\
\hline \multicolumn{4}{|c|}{ Cox and Snell's R square $=0.598$} \\
\hline \multicolumn{4}{|c|}{$\rho_{c v}^{2}=0.579493$, Shrinkage coefficient $(\lambda)=0.018507137$} \\
\hline
\end{tabular}

Note: $\mathbf{R}$ indicates reference category.

\section{Conclusions}

In the present study, it is found that the mean age at menarche of Bangladeshi school going girls of classes five, six, seven and eight was 12.32 . This study exhibited that the father monthly income of menarche respondent's was high than the non menarche respondent's father monthly income. The mean difference between menarche and non-menarche respondent's father income was 2772.622. It was displayed that the menarche students were much spent their time by watching TV and by playing and the mean difference is 0.3600 and 0.1041 respectively. The mean difference between height, weight and BMI was 6.7825, 9.15 and 2.6824 respectively, that means the taller students reached menarche earlier than the shorter girls and the heavier girls reached menarche earlier than the thinner girls and also getting larger BMI girls reached earlier than that of lower BMI girls. Height, weight, father income, BMI, time spent by watching television and father educational qualification were highly significant with the association of early menarche for school going girls. Finally, the logistic regression analysis showed that height, weight and time spent by watching TV of the respondents had positive effects on age at menarche.

\section{REFERENCES}

[1] Kelsey, J. (1993). Breast cancer. Epidemiologic Reviews., 15: $1-263$.

[2] Copper, G., Ephross, S., Weinberg, C., Baird, D. and Sandler, D. (1998). Menstrual and reproductive risk factors for ischemic heart disease. Epidemiology., 10: 255-259.

[3] Rees, M (1995). The age at menarche. ORGYN., 4:2-4.

[4] Riley, A.P., Huffman, S.L. and Chowdhury, A.k. (1989). Age at menarche and postmenarcheal growth in rural Bangladeshi females. Ann Hum Biol., 16: 347-359.

[5] Wyshak, G. and Frisch, R. (1982). Evidence for a secular trend in age at menarche, New England Journal of Medicine, 306: 1033-1035.

[6] Roberts, D. and Dann, T. (1975). A 12 year study of menarcheal age, British Journal Of Preventive and Social Medicine, 29: 31-39.

[7] Hauspie, R., Vereauteren, M. and Susanne, C. (1997). Seqular changes in growth and maturation: an update. Acta Padiatrica., 423:20-27.

[8] Chowdhury, A.K, Huffman, S.L, and Curlin, G.T. (1977). Malnutririon menarche and marriage in rural Bangladesh. 24: 316-325.

[9] Haq, M.N. (1984). Age at menarche and the related issue: a pilot study on urban School girls. J Youth Adolesc., 13:559-567.

[10] Ogata (1979). Age at menarche and marriage in Bangladesh women. J Trop Med Hyg., 82: 68-74.

[11] Cox, D. R. (1958). The regression analysis of binary sequences (with discussion), J.R. Statist. Soc., B20, pp.215-242.

[12] Cox, D. R. (1970). The analysis of binary data, London: Methuen, Chapman and Hall Ltd.

[13] Fox, J. (1984). Linear statistical models and related methods, Wiley and Sons, New York.

[14] Stevens, J. (1996). Applied Multivariate Statistics for the Social Sciences, Third Edition, Lawrence Erlbaum Associates, Inc., Publishers, New Jersey.

[15] Islam, Md. Rafiqul (2003). Modeling of Demographic Parameters of Bangladesh-An Empirical Forecasting, Unpublished Ph.D. Thesis, Rajshahi University.

[16] Islam, Md. Rafiqul. (2005). Construction of Female Life Table from Male Widowed Information of Bangladesh, Pakistan J. of Statistics, Vol. 21(3), Page 275-284.

[17] Islam, Md. Rafiqul, Islam, Md. Nurul, Ali, Md. Ayub and Mostofa, Md. Golam (2003). Construction of Male Life Table from Female Widowed Information of Bangladesh, International J. of Statistical Sciences, Vol. 2, Dept. of Statistics, University of Rajshahi, Bangladesh, Page 69-82.

[18] Islam, Md. Rafiqul, Islam, Md. Nurul, Ali, M. Korban \& Mondal, Md. Nazrul Islam (2005). Indirect Estimation and Mathematical Modeling of Some Demographic Parameters of Bangladesh, The Oriental Anthropologist, Vol. 5(2), Page $163-171$. 